\title{
The Presence of Mycotoxins in Human Amniotic Fluid
}

\author{
Karolina Gromadzka 1,*DD, Jakub Pankiewicz ${ }^{2}$, Monika Beszterda ${ }^{3}$, Magdalena Paczkowska ${ }^{4}$, \\ Beata Nowakowska ${ }^{4}$ and Rafał Kocyłowski ${ }^{2}$ (D)
}

1 Department of Chemistry, Poznań University of Life Sciences, ul. Wojska Polskiego 75, 60-625 Poznań, Poland

2 Premedicare, NEW MED Medical Center, ul. Drużbickiego 13, 60-693 Poznań, Poland; biuro@new.med.pl (J.P.); rkocylow@gmail.com (R.K.)

3 Department of Food Biochemistry and Analysis, Poznań University of Life Sciences, ul. Mazowiecka 48, 60-623 Poznań, Poland; monika.beszterda@up.poznan.pl

4 The Institute of Mother and Child, ul. Kasprzaka 17a, 01-211 Warszawa, Poland; magdalena.paczkowska@imid.med.pl (M.P.); beata.nowakowska@imid.med.pl (B.N.)

* Correspondence: karolina.gromadzka@up.poznan.pl

check for

updates

Citation: Gromadzka, K.; Pankiewicz, J.; Beszterda, M.; Paczkowska, M.; Nowakowska, B.; Kocyłowski, R. The Presence of Mycotoxins in Human Amniotic Fluid. Toxins 2021, 13, 409. https:// doi.org/10.3390/toxins13060409

Received: 27 April 2021

Accepted: 8 June 2021

Published: 9 June 2021

Publisher's Note: MDPI stays neutral with regard to jurisdictional claims in published maps and institutional affiliations.

\begin{abstract}
Mycotoxin exposure assessments through biomonitoring studies, based on the analysis of amniotic fluid, provides useful information about potential exposure of mothers and fetuses to ubiquitous toxic metabolites that are routinely found in food and the environment. In this study, amniotic fluid samples $(n=86)$ were collected via abdominal amniocentesis at $15-22$ weeks of gestation from pregnant women with a high risk of chromosomal anomalies or genetic fetal defects detected during 1st trimester prenatal screening. These samples were analyzed for the presence of the most typical Aspergillus, Penicillium and Fusarium mycotoxins, with a focus on aflatoxins, ochratoxins and trichothecenes, using the LC-FLD/DAD method. The results showed that the toxin was present in over $75 \%$ of all the tested samples and in $73 \%$ of amniotic fluid samples from fetuses with genetic defects. The most frequently identified toxins were nivalenol $(33.7 \%)$ ranging from <LOQ to $4037.6 \mathrm{ng} / \mathrm{mL}$, and aflatoxins (31.4\%), including aflatoxin G1, ranging from <LOQ to $0.4 \mathrm{ng} / \mathrm{mL}$. Ochratoxin A and deoxynivalenol were identified in $26.7 \%$ and $27.9 \%$ of samples, respectively. Bearing in mind the above, the detection of mycotoxin levels in amniotic fluid is useful for the estimation of overall risk characterization with an attempt to link the occurrence of fetal abnormalities with exposure to mycotoxins in utero.
\end{abstract}

Keywords: mycotoxins; Aspergillus; Fusarium; amniotic fluids; fetal defects; genetic abnormalities

Key Contribution: The presence of mycotoxins in amniotic fluids may pose a risk to the fetus.

\section{Introduction}

To date, it is believed that the pregnancy and the good health of newborns are particularly influenced by maternal infections, hypertensive disease in pregnancy, smoking and insufficient maternal nutrition [1,2]. Moreover, environmental pollution has recently been added to this list of threats to the health of the fetus. In addition, food consumed by pregnant women may contain dangerous natural products such as mycotoxins.

Mycotoxins are hazardous metabolites which are produced by fungi. Those fungi are divided into two groups: field fungi that invade before harvest (mainly Fusarium species), and storage fungi that occur only after harvest (Aspergillus and Penicillium species). Mycotoxins show harmful effects on humans, animals and plants, which result in diseases and economic losses. Worldwide feed and food contamination with those secondary metabolites is a significant problem [3-5].

Food can be contaminated with toxins at numerous stages in the food chain [3] and Aspergillus, Alternaria, Claviceps, Fusarium, Penicillium and Stachybotrys are the most common genera of mycotoxigenic fungi. So far, more than 400 mycotoxins have been identified. Scientific attention is mainly focused first of all on carcinogens and/or metabolites that 
are well known as being toxic to humans and animals. Aflatoxins (aflatoxin B1 (AFLB1)), ochratoxins (ochratoxin A (OTA)), fumonisins (fumonisin $\mathrm{B}_{1}\left(\mathrm{FB}_{1}\right)$ ), zearalenone (ZEA) and trichothecenes (deoxynivalenol (DON)) are considered to be the most significant mycotoxins in agriculture and in the food industry [6]. These substances are toxic to vertebrates and humans at low concentrations, with various acute and chronic effects, depending on the species. Analyzing a given species, the effect of mycotoxins on health is influenced by age, sex, diet, weight, the presence of other toxic metabolites (synergistic and antagonistic effects) and pharmacologically active substances, and also by exposure to infectious agents [5,7]. Most of the mycotoxins known so far have been grouped according to their toxic properties, under chronic conditions, as teratogenic, mutagenic or carcinogenic. They can also be grouped according to their target place of action, which results in the designations of neuro-, hemo-, nephron-, hepato-, dermato- and immunotoxins [8]. Human exposure to mycotoxins can result from the consumption of food contaminated with toxins (mainly cereal food), from the transfer of mycotoxins and their metabolites in animal products like meat and eggs or from exposure to air containing dust and toxins $[4,5]$.

To prove that a disturbance is due to mycotoxicosis, a dose-response relationship between the substance and the disease must be demonstrated. In the case of human populations, this dependence requires epidemiological studies. Additional evidence is provided when the typical symptoms of suspected mycotoxicosis in humans are induced reproducibly in animal models through exposure to a given mycotoxin. Human exposure to mycotoxins is further determined by environmental or biological monitoring. In environmental monitoring, metabolites of toxigenic fungi are measured in air, food or other samples. In biological monitoring, the presence of mycotoxins, adducts and residues is tested directly in tissues, fluids and excreta [9].

So far, there is no information about how toxins found in food affect the health of pregnant women and the condition of the fetus. The available work focuses on aflatoxins and their content in blood. The assessment of the concentration of aflatoxins in the maternal and cord blood and its influence on birth weight has been performed in various countries and populations $[6,7,10-16]$. However, not much is known about the presence of mycotoxins in the amniotic fluid [10]. The composition of the amniotic fluid (AF) is relevant to the development of the fetus and reflects both fetal and maternal compartments. During pregnancy, physiological and metabolic changes in the organs of a woman depend on the requirements of the growing fetus. The composition of AF is influenced by the mother's diet, including essential nutrients, and the exposure scale to toxic substances. Overexposure to toxic substances can be harmful to the health of both the fetus and the pregnant woman $[11,12]$.

The fetus has a unique sensitivity to deleterious health effects resulting from in utero exposure to environmental pollutions, because of rapid cell proliferation, poor detoxification or elimination capacity, high absorption rate and immature repairing mechanisms [13]. Human epidemiological studies have indicated that in utero exposure to xenobiotics could contribute to the development of cancer in early life, or can even predispose the fetus to chronic disease and carcinogenesis later in life. In the case of the excretion of xenobiotics to fetal urine, this ends up in the amniotic fluid, which is then subject to subsequent fetal swallowing. Considering the genotoxic, neurotoxic, nephrotoxic and endocrinedisrupting properties of fungal metabolites, early exposure and continuous circulation of these substances in the fetus throughout pregnancy could interfere with critical fetal development [13].

Based on the currently available experimental results, it is probable that transplacental transfer of mycotoxins-metabolites of low molecular weight-occurs from the early gestational stage and accumulates in the fetal circulation towards the end of pregnancy. Taking the above into account, the major aim of this study was the analysis of the presence of mycotoxins in amniotic fluids taken from women with abnormalities in the development of the fetus, including genetic defects. 


\section{Results and Discussion}

In this study, 86 samples of amniotic fluids were analyzed for the presence of mycotoxins. The toxins that formed in the field (zearalenone, deoxynivalenol and nivalenol) and those created during the storage of grain products (ochratoxin A and aflatoxins B1, B2, G1 and G2) were analyzed. Toxins were selected for research on the basis of previous studies and their frequency and harmfulness to humans and animals. Deoxynivalenol and nivalenol belong to the trichothecenes. These compounds are toxic to humans and animals. They cause hemorrhages and can lead to cardiac arrest and death [3,4,9]. Zearalenone is a lactone of resorcinic acid-this compound is classified as phytoestrogenic, which in practice means it has a special effect on human and animal reproduction. The effect of zearalenone is several times stronger than that of natural estrogen [3]. Aflatoxins and ochratoxin A belong to the storage mycotoxins, i.e., they are formed during improper storage. The first is mutagenic, teratogenic and hepatotoxic [10]. On the other hand, ochratoxin A belongs to the group of ochratoxins with mutagenic activity, and also has nephro-, neuro- and immunotoxic properties [13].

Amniotic fluid samples were collected between weeks 15 and 22 of gestation from women suspected for fetal genetic abnormalities during first trimester screening (between 11 and 14 weeks). Among the tested samples of amniotic fluid, 71 came from fetuses with no genetic defects, whereas 15 came from women whose offspring were confirmed to have genetic disorders. The conducted research showed that the toxin was present in over $74 \%$ of the tested samples and in $73 \%$ of amniotic fluid samples from fetuses with chromosomal aberrations (Table 1).

Table 1. The research data and summary of the presence of mycotoxins in human amniotic fluid samples with normal and abnormal genetic results.

\begin{tabular}{cccc}
\hline \multirow{2}{*}{ Number of Samples Tested } & Normal Genetic Samples & Chromosomal Aberration Samples & All Samples \\
\cline { 2 - 4 } & $\mathbf{7 1}$ & $\mathbf{1 5}$ & $\mathbf{8 6}$ \\
\hline Toxins in amniotic fluid & Normal genetic samples (\%) & Chromosomal aberration samples (\%) & All samples (\%) \\
\hline All toxins & 74.6 & 73.3 & 0 \\
\hline Zearaleone & 0 & 0 & 27.4 \\
\hline Deoxynivalenol & 29.6 & 20.0 & 27.9 \\
\hline Nivalenol & 28.2 & 26.6 & 26.7 \\
\hline Ochratoxin A & 28.2 & 20.0 & 1.2 \\
\hline Aflatoxin B1 & 1.4 & 0 & 10.5 \\
\hline Aflatoxin B2 & 9.8 & 13.3 & 17.4 \\
\hline Aflatoxin G1 & 16.9 & 20.0 & 10.5 \\
\hline Aflatoxin G2 & 9.8 & 13.3 & \\
\hline
\end{tabular}

The available literature generally lacks information on the occurrence of mycotoxins in amniotic fluid. However, one can find information about the presence of these compounds in the blood of the mother or the cord blood. These data mainly refer to storage mycotoxins, especially aflatoxins [10-16].

According to Kyei et al. [17] there is already some evidence to suggest that exposure to toxic metabolites of fungi during pregnancy could have deleterious effects on pregnancy outcomes. However, given the slight number of studies, especially on effects of Fusarium toxins, more studies are necessary for a more comprehensive understanding of the effects of various mycotoxins on maternal and fetal health condition and to inform public health policies and interventions. 
During our research, aflatoxins were detected in $31.4 \%$ of all analyzed samples. The most frequently aflatoxin was G1, which was present in $17.4 \%$ of the samples at concentrations ranging from $<\mathrm{LOQ}$ to $0.4 \mathrm{ng} / \mathrm{mL}$. Aflatoxins $\mathrm{G} 2$ and $\mathrm{B} 2$ were present in $10.5 \%$ of the samples, with maximum concentrations of 1.9 and $0.4 \mathrm{ng} / \mathrm{mL}$, respectively. Aflatoxin B1 was detected in only one analyzed sample $(1.2 \%)$ at a concentration of $0.2 \mathrm{ng} / \mathrm{mL}$. The results show that among the amniotic fluid samples in which the aflatoxin was present, genetic defects were found in $22.2 \%$ of fetuses (Tables 1 and 2; Supplementary Materials). Thus, no relationship was found between the presence of aflatoxins and the occurrence of genetic defects in the fetus.

Table 2. Aflatoxin concentration in positive samples of amniotic fluids.

\begin{tabular}{|c|c|c|c|c|c|c|}
\hline \multirow{2}{*}{ nr } & \multirow{2}{*}{ Nr PD } & \multirow{2}{*}{ Test Results aCGH } & \multicolumn{4}{|c|}{ AFLs [ng/mL] } \\
\hline & & & G1 & G2 & B2 & B1 \\
\hline 1 & 2883 & incorrect & nd & nd & $<$ LOQ & nd \\
\hline 2 & 2887 & correct & nd & nd & nd & $<\mathrm{LOQ}$ \\
\hline 3 & 2888 & incorrect & nd & 0.9 & nd & nd \\
\hline 4 & 2902 & correct & 0.3 & nd & nd & nd \\
\hline 5 & 2904 & incorrect & $<$ LOQ & $<$ LOQ & nd & nd \\
\hline 6 & 2906 & correct & $<\mathrm{LOQ}$ & $<$ LOQ & nd & nd \\
\hline 7 & 2907 & incorrect & $<$ LOQ & nd & nd & nd \\
\hline 8 & 2920 & correct & $<$ LOQ & $<$ LOQ & $<\mathrm{LOQ}$ & nd \\
\hline 9 & 2921 & incorrect & nd & nd & 0.4 & nd \\
\hline 10 & 2930 & correct & $<$ LOQ & nd & nd & nd \\
\hline 11 & 2933 & correct & nd & $<$ LOQ & nd & nd \\
\hline 12 & 2936 & correct & nd & nd & $<\mathrm{LOQ}$ & nd \\
\hline 13 & 2940 & correct & nd & $<$ LOQ & nd & nd \\
\hline 14 & 2941 & correct & $<\mathrm{LOQ}$ & $<$ LOQ & $<\mathrm{LOQ}$ & nd \\
\hline 15 & 2947 & correct & $<\mathrm{LOQ}$ & nd & nd & nd \\
\hline 16 & 2949 & incorrect & 0.3 & nd & nd & nd \\
\hline 17 & 2950 & correct & 0.2 & nd & nd & nd \\
\hline 18 & 2951 & correct & nd & $<$ LOQ & nd & nd \\
\hline 19 & 2953 & correct & nd & nd & $<\mathrm{LOQ}$ & nd \\
\hline 20 & 2954 & correct & 0.2 & nd & nd & nd \\
\hline 21 & 2966 & correct & nd & $<$ LOQ & nd & nd \\
\hline 22 & 2994 & correct & 0.4 & nd & nd & nd \\
\hline 23 & 3094 & correct & 0.02 & nd & nd & nd \\
\hline 24 & 3113 & correct & nd & nd & 0.1 & nd \\
\hline 25 & 3114 & correct & nd & nd & 0.2 & nd \\
\hline 26 & 3115 & correct & 0.1 & nd & 0.2 & nd \\
\hline 27 & 3227 & correct & 0.1 & nd & nd & nd \\
\hline
\end{tabular}

The first studies on the aflatoxin content in the mother's blood and in the cord blood were carried out in 1989 by De Vries et al. [18]. According to the authors, aflatoxins (AFLs) were detected in concentrations ranging from 12 to $11,574 \mathrm{pg} / \mathrm{mL}$ in $53 \%$ of maternal blood samples, and in concentrations ranging from 17 to $6819 \mathrm{pg} / \mathrm{mL}$ in $37 \%$ of cord blood samples. There was a relationship between sex and AFL content in maternal blood at delivery on birth weight because in AFL-positive mothers the mean birth weight of 
female infants was about $255 \mathrm{~g}$ lower than that of females born to AFL-negative mothers. An inverse dependence was observed in the case of male infants, which means the birth weights of males born to AFL-negative mothers was $132 \mathrm{~g}$ lower than that of males born to AFL-positive mothers.

According to the literature, aflatoxins are present in the cord blood of $38 \%$ to $91 \%$ of tested samples at concentrations of $4-10,440 \mathrm{pg} / \mathrm{mL}$. There is also no clear information on the impact of the presence of toxins on the birth weight [17,19-24]. As for maternal blood, this type of toxin was detected in $53 \%$ and $68 \%$ of the tested samples at concentrations of $12-11,574 \mathrm{pg} / \mathrm{mL}[18,20]$. According to the latest research, aflatoxin was found in all blood samples taken from pregnant women and their content ranged from 0.44 to $268.7 \mathrm{pg} / \mathrm{mL}$ [16]. The amount of aflatoxins in the mother's blood will certainly depend on the geographic region and diet.

Most of the work on the presence of mycotoxins and their impact on the health conditions of fetuses and newborns refer to the presence of these compounds in the mother's blood and cord blood. Therefore, comprehensive research is extremely important in order to draw the right conclusions. Ibeh et al. [10] also examined the content of toxins in amniotic fluids. Aflatoxin values above $20 \mathrm{ppb}$ were obtained in $74.1 \%$ of samples of the amniotic fluid; $67.2 \%$ of neonatal cord blood samples and $62.4 \%$ of venous maternal blood samples. According to the authors, these results suggest that these mycotoxins present in the maternal blood cross the placental barrier and can accumulate in the fetus, which further explains the high amount of aflatoxins in the amniotic fluid and the intrauterine exposure to toxins.

In addition to aflatoxins, Jonsyn et al. [19] also studied ochratoxin A concentrations in cord blood. This toxin was present in $25 \%$ of the tested samples at concentrations of 200-3500 pg/mL. Exposure to ochratoxin A (OTA) had no effect on boys' birth weights. The average birth weights of girls exposed to the toxin were $190 \mathrm{~g}$ lower than those of girls who were not exposed. In the Czech Republic, OTA was detected in almost all tested serum samples $(n=115)$ from pregnant women in amounts up to $1.13 \mu \mathrm{g} / \mathrm{L}$, and in women of the child-rearing age $(n=100)$ up to $0.35 \mu \mathrm{g} / \mathrm{L}[25,26]$. Simultaneously, these data were correlated with OTA dietary exposure assessments. OTA has also been identified in serum samples $(n=98)$ of pregnant women from Egypt [13], where it was in the range of 0.20-1.53 ng/mL and the estimated OTA concentration in fetuses was 0.40-3.06 ng $/ \mathrm{mL}$. In turn, Ritieni et al. [14] examined ochratoxin in amniotic fluid. OTA was present in only one of 21 tested samples in a concentration of $4.26 \mathrm{ng} / \mathrm{mL}$. In our studies, OTA was found to be present in $26.7 \%$ of examined samples. The toxin concentration was in the range of $<$ LOQ to $0.7 \mathrm{ng} / \mathrm{mL}$. Figure 1a shows all the samples in which the amount of the toxin could be analyzed (16 samples). In the remaining cases, the OTA concentration was below the quantitative limit. Only three OTA samples were found in the amniotic fluid of the fetuses which had genetic defects (Table 1). Although the presence of toxins clearly does not affect the occurrence of genetic defects, it may have an impact on the health of the fetus or its birth weight.

The presence of OTA in the amniotic fluid is in agreement with the literature, where the carry-over of the mycotoxin through the placenta has been reported $[27,28]$.

During this study, the toxins metabolized by the Fusarium species were also analyzed. There is no information in the literature on the presence of deoxynivalenol, nivalenol (NIV) and zearalenone in amniotic fluids and their effects on the fetus. The chromatographic analysis showed that zearalenone was not present in all 86 samples of amniotic fluid. Our hypothesis is that this toxin does not cross the placenta; however, there is no information in the literature about the presence of this toxin in the cord and maternal blood. Therefore, further studies are needed to confirm that this toxin does not pose a risk to the fetus. 

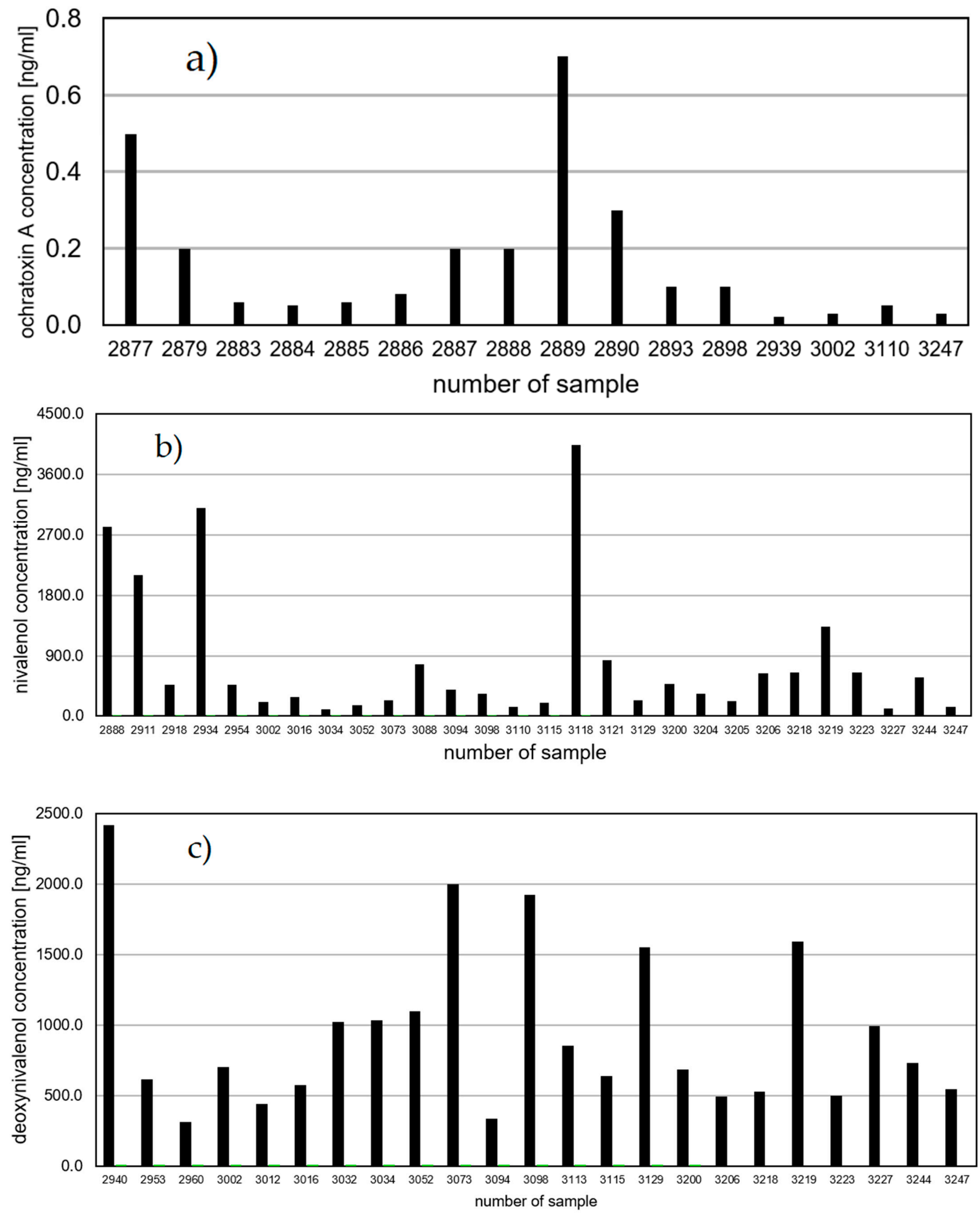

Figure 1. Mycotoxin concentrations in amniotic fluid (ng/mL)—(a) ochratoxin $\mathrm{A},(\mathbf{b})$ nivalenol, (c) deoxynivalenol. 
The most commonly detected toxin in the amniotic fluid was nivalenol. It was present in $33.7 \%$ of the tested samples at concentrations from <LOQ ( 1 sample) to $4037.6 \mathrm{ng} / \mathrm{mL}$ (Table 1; Figure 1b). The presence of the toxin in such large amounts is disturbing, although in the case of this toxin there was also no relationship between its presence and the occurrence of genetic defects. The frequent occurrence of nivalenol in pregnant women in Poland is justified because NIV is one of the most common mycotoxins in our country. NIV was present in 29 tested samples. Of these, four fetuses had genetic defects (13.8\%). In animal studies NIV shows higher acute toxicity than DON, with oral $\mathrm{LD}_{50}$ values in mice of 39 and $78 \mathrm{mg} \cdot \mathrm{kg}^{-1}$ for NIV and DON, respectively [29]. At the molecular level, NIV and DON demonstrate multidirectional inhibitory effects on the primary metabolism of eukaryotic cells, including the inhibition of DNA, RNA and protein synthesis. Such damage leads to disturbed cell proliferation in tissues with high rates of cell turnover such as bone marrow, intestinal mucosa, spleen and thymus [30-32]. As demonstrated by Cheat et al. [30], NIV has a stronger influence on the intestinal mucosa than DON (NIV enhanced apoptosis at the top of villi and decreased the proliferative/apoptotic cell ratio by about half), both in vitro and in vivo, which highlights the inevitability of a specific hazard characterization for NIV risk assessments.

The second trichothecenes toxin analyzed in the amniotic fluid was deoxynivalenol. It was present in 24 of 86 tested samples (Table 1; Figure 1c). The DON content in the amniotic fluids ranged from <LOQ (1 sample) to $2417.8 \mathrm{ng} / \mathrm{mL}$. Only three samples in which DON was found were from women who gave birth to a child with a genetic defect. There is a lack of information on the presence of deoxynivalenol in tissues, fluids and excreta, and on its potential impact on the health of the mother and the fetus.

So far, the content of DON has been analyzed only in the urine of pregnant women [33]. Total DON (free-form and DON glucuronide combined) was identified in $88.1 \%$ and $83.3 \%$ of women on days 1 and 2, respectively. On day 1 the mean concentration of total DON was 29.7 (in the range from 0 to 436), and on day 2 it was $28.7 \mathrm{ng} / \mathrm{mL}$ urine (range 0-167). The high incidence of the presence of DON in the urine of pregnant females from the UK in this study confirms its ubiquitous presence in cereal food products. According to Rodríguez-Carrasco and coworkers [34], after $49.2 \mu \mathrm{g}$ of DON daily intake, a urinary daily excretion of $35.2 \mu \mathrm{g}$ was identified in humans, representing $68.3 \%$ of the established DON provisional maximum tolerable daily intake (PMTDI).

One of limitations of our study is the use of human amniotic fluid samples from high-risk pregnancies only. Such samples from normal healthy pregnancies could be collected, only if the woman agrees to amniocentesis. Due to the invasive and therefore risky character of $\mathrm{AC}$, informed consent is very difficult to obtain when not medically indicated. However, samples with normal genetic results may constitute a kind of control subgroup for genetically abnormal samples in the high-risk population.

\section{Conclusions}

The limited developmental toxicology literature implies possible adverse effects of mycotoxins on fetal growth, viability and postnatal development. In our study, amniotic fluid samples collected in the second trimester (15-22 weeks of gestation) via amniocentesis revealed the presence of mycotoxins in more than $75 \%$ of the tested samples and in $73 \%$ of amniotic fluid samples from fetuses with genetic defects. The most frequently identified toxin was nivalenol, which is simultaneously one of the most common mycotoxins contaminating crops in Poland. Moreover, the presence of aflatoxins ochratoxin A and deoxynivalenol were also observed in $26.7 \%$ to more than $31 \%$ of samples. The detection of several mycotoxins in amniotic fluid indicates that, in addition to blood borne in utero exposure, the fetus is also ingesting and bathing in low levels of these xenobiotics, which may exacerbate the risk of developing chromosomal anomalies or genetic fetal defects. 


\section{Materials and Methods}

\subsection{Chemicals and Reagents}

Mycotoxin standards (AFLG1, AFLG2, AFLB1, AFLB2, OTA, DON, NIV, ZEA), HPLCgrade solvents and all reagents for extraction and purification process were obtained from Sigma-Aldrich (Steinheil, Germany). Water (HPLC grade) was obtained from Milli-Q systems (Millipore, Billerica, MA, USA).

\subsection{Study Design}

This was an exploratory study to determine the levels of mycotoxins in AF in the second trimester, between 15 and 22 weeks of gestation. The AF samples were collected during routine diagnostic amniocentesis in pregnant women with a high risk of chromosomal abnormalities.

\subsection{Biospecimen Collection and Preparation of Amniotic Fluid}

Amniotic fluid (AF) samples were obtained $(15-20 \mathrm{~mL})$ for genetic analysis following routine diagnostic amniocentesis at 15-22 weeks of gestation. Samples were collected by means of transabdominal aspiration using sterile 22-25 G spinal and diagnostic puncture needles and plastic syringes that were free from organic and non-biological contamination. Each sample of the fresh amniotic fluid was centrifuged for $5 \mathrm{~min}$ at $1300 \mathrm{rpm}$. Next, $2 \mathrm{~mL}$ of supernatant was transferred to a new $2 \mathrm{~mL}$ tube and frozen at $-20^{\circ} \mathrm{C}$ for further mycotoxin analyses.

Genomic DNA for chromosomal microarray analysis (CMA) was extracted from the fresh amniotic fluids (AFs) using the Sherlock kit (A\&A Biotechnology, Poland) according to the manufacturer's recommendations. Array comparative genomic hybridization (array CGH) was performed using 60K microarrays $8 \times 60 \mathrm{~K}$ from Oxford Gene Technology (CytoSure ISCA, v3). The array contained 51,317-mer oligonucleotide probes, covering the whole genome, with an average spatial resolution of $60 \mathrm{~Kb}$.

Procedures for DNA denaturation, labeling, hybridization and washing were performed according to the manufacturer's instructions. Genomic DNA was labeled using a CytoSure Labeling Kit (Oxford Gene Technology, Begbroke, United Kingdom), with no enzyme digestion. Hybridization was performed between 24 to $48 \mathrm{~h}$ at $65{ }^{\circ} \mathrm{C}$ in a rotator oven (Agilent, Santa Clara, CA, USA). Arrays were washed using Agilent wash buffer 1 and 2, scanned using an Agilent Technologies microarray scanner and the signal intensities were measured using Feature Extraction software (Agilent Technologies, CA, USA). Agilent Feature Extraction software (V10.0) was used to quantify all scanned images.

CytoSure Interpret Software (Oxford Gene Technology, Begbroke, UK) was used to perform data analysis based on the reference genome (NCBI37/hg19).

In most cases, part of the amniotic fluid sent for aCGH was also used for cytogenetic karyotype analysis. Amniocytes were cultured using in situ vessels. Colony growth and mitotic activity were controlled daily after the 8th day of culture. Metaphase chromosomes were prepared according to the standard procedures of GTG banding.

\subsection{Mycotoxins Determination}

An aliquot of 500 microliters of each sample (amniotic liquid) was added of $2.5 \mathrm{~mL}$ of a $0.1 \mathrm{M} \mathrm{MgCl}_{2}$ solution and the mixture was stirred; subsequently, $2.5 \mathrm{~mL}$ of chloroform were added, the solution was acidified with $\mathrm{HCl} 6 \mathrm{~N}$ and the mixture was stirred again for $2 \mathrm{~min}$. The samples were then ice-cooled for $20 \mathrm{~min}$ and then centrifuged at $4{ }^{\circ} \mathrm{C}$ for $10 \mathrm{~min}$ at $3000 \mathrm{rpm}$. The organic phase was separated and the organic solvent was evaporated using a ThermoSavant centrifugal evaporator (Savant Instruments Inc., Farmingdale, NY, USA). Before the chromatographic analysis the samples were dissolved in 200 microliters of a solution of mobile phase.

The toxin content was determined using the chromatographic system: a Waters 2695 high performance liquid chromatograph, a Waters 2475 Multi $\lambda$ Fluorescence Detector and/or a Waters 2996 Array Detector. The quantification limits (LOQs) were determined by 
multiplying the detection limits (LODs) by 3.3. The LODs of the methods were calculated using a signal-to-noise ratio of 3:1.

Zearalenone determination was carried out using a fluorescence detector and the excitation and emission wavelengths were 274 and $440 \mathrm{~nm}$, respectively. The reserve-phase column was a C-18 Nova Pak column $(3.9 \times 150 \mathrm{~mm})$, whereas the mobile phase was acetonitrile:water:methanol $(46: 46: 8, v / v / v)$, at a flow rate of $0.5 \mathrm{~mL} / \mathrm{min}$. Quantification of ZEA was performed by measuring the peak areas at the ZEA retention time according to the relevant calibration curve (correlation coefficient $R=0.9998$ ). The limit of ZEA qualification was $0.06 \mathrm{ng} / \mu \mathrm{L}$. In order to confirm the presence of zearalenone, a photodiode array detector was used.

For deoxynivalenol and nivalenol determination, the trichothecenes were quantified by means of the HPLC method using a C-18 Nova Pak column $(3.9 \times 300 \mathrm{~mm})$ and a Waters 2996 Array Detector $(\lambda \max =224 \mathrm{~nm}$ for DON and NIV). DON and NIV were eluted from the column with a $25 \%$ water solution of methanol (flow rate $0.7 \mathrm{~mL} \mathrm{~min}^{-1}$ ) with retention times of 11.72 and $7.46 \mathrm{~min}$, respectively. The detection limit for DON and NIV was $0.01 \mu \mathrm{g} / \mathrm{mL}$. The quantification limit was $0.033 \mu \mathrm{g} / \mathrm{mL}$. Positive results (on the basis of retention times) were confirmed by means of HPLC analysis and through comparisons with the relevant calibration curve (correlation coefficients for NIV and DON are 0.9994 and 0.9997 , respectively).

The determination of OTA was carried out in a high-performance liquid chromatography (HPLC) system equipped with a fluorescence detector. Liquid chromatography was performed on a C-18 Nova Pak column $(3.9 \times 150 \mathrm{~mm})$ column, operated at $0.9 \mathrm{~mL} / \mathrm{min}$ with acetic acid:acetonitrile:water (2:99:99) as the mobile phase. The excitation wavelength of the fluorescence detector was set at $333 \mathrm{~nm}$ and the emission wavelength was $477 \mathrm{~nm}$. For the quantitative determination of OTA, peak areas of the samples were correlated with the concentrations according the calibration curve. The qualification limit for OTA determination was $0.02 \mathrm{ng} / \mathrm{mL}$.

Aflatoxin (G1, G2, B1, B2) quantities of samples were determined using HPLC with fluorescent detection and a C-18 Nova Pak column $(3.9 \times 150 \mathrm{~mm})$. Aflatoxins were separated in the HPLC column with a mobile phase of water:methanol:acetonitrile (60:30:15) at a flow rate $1.2 \mathrm{~mL} / \mathrm{min}$. Fluorescence detection was performed at an excitation wavelength of 365 $\mathrm{nm}$ and an emission wavelength of $440 \mathrm{~nm}$. Positive results (on the basis of retention times) were confirmed via comparisons with the relevant calibration curve. The qualification limit for aflatoxins G1 and G2 was $0.02 \mathrm{ng} / \mathrm{mL}$ and for B1 and B2 it was $0.03 \mathrm{ng} / \mathrm{mL}$.

\subsection{Ethics Approval and Consent to Participate}

The study protocol was approved by the Bioethics Commission at Poznan University of Medical Sciences (approval no. 297/17, from 2 March 2017). Informed consent was obtained from all women. The study was performed in accordance with the Helsinki Declaration.

Supplementary Materials: The following are available online at https://www.mdpi.com/article/10 $.3390 /$ toxins13060409/s1, Table S1.

Author Contributions: Conceptualization, K.G. and R.K.; methodology, K.G. and R.K.; software, J.P.; validation, M.B., M.P., B.N. and K.G.; formal analysis, K.G.; investigation, J.P.; resources, J.P., R.K.; data curation, B.N. and M.P.; writing—original draft preparation, K.G. and R.K.; writing-review and editing, all authors; visualization, K.G. and R.K.; supervision, R.K.; project administration, K.G. and R.K.; funding acquisition, J.P. and M.B. All authors have read and agreed to the published version of the manuscript.

Funding: This research was founded by a NEW MED Medical Center Grant for Original Research. The funders had no role in the design of the study; in the collection, analyses, or interpretation of data; in the writing of the manuscript, or in the decision to publish the results. 
Institutional Review Board Statement: The study was conducted according to the guidelines of the Declaration of Helsinki, and approved by the Bioethics Commission at Poznan University of Medical Sciences (approval no. 297/17 from 2 March 2017).

Informed Consent Statement: Informed consent was obtained from all subjects involved in the study. Data Availability Statement: Not applicable.

Conflicts of Interest: The authors declare no conflict of interest.

\section{References}

1. Kramer, M.S. The Epidemiology of Adverse Pregnancy Outcomes: An Overview. J. Nutr. 2003, 133, 1592S-1596S. [CrossRef] [PubMed]

2. Ota, E.; Ganchimeg, T.; Morisaki, N.; Vogel, J.P.; Pileggi, C.; Ortiz-Panozo, E.; Souza, J.P.; Mori, R.; WHO Multi-Country Survey on Maternal and Newborn Health Research Network. Risk Factors and Adverse Perinatal Outcomes among Term and Preterm Infants Born Small-for-Gestational-Age: Secondary Analyses of the WHO Multi-Country Survey on Maternal and Newborn Health. PLoS ONE 2014, 9, e105155. [CrossRef] [PubMed]

3. Bennett, J.W.; Klich, M. Mycotoxins. Clin. Microbiol. Rev. 2003, 16, 497-516. [CrossRef] [PubMed]

4. Tola, M.; Kebede, B. Occurrence, importance and control of mycotoxins: A review. Cogent Food Agric. 2016, 2, 1191103. [CrossRef]

5. Zain, M.E. Impact of mycotoxins on humans and animals. J. Saudi Chem. Soc. 2011, 15, 129-144. [CrossRef]

6. Huffman, J.; Gerber, R.; Du, L. Recent advancements in the biosynthetic mechanisms for polyketide-derived mycotoxins. Biopolymers 2010, 93, 764-776. [CrossRef] [PubMed]

7. Milićević, D.R.; Škrinjar, M.; Baltić, T. Real and Perceived Risks for Mycotoxin Contamination in Foods and Feeds: Challenges for Food Safety Control. Toxins 2010, 2, 572-592. [CrossRef] [PubMed]

8. Niessen, L. PCR-based diagnosis and quantification of mycotoxin producing fungi. Int. J. Food Microbiol. 2007, 119, 38-46. [CrossRef] [PubMed]

9. Hsieh, D. Potential human health hazards of mycotoxins. Mycotoxins and phytotoxins. In Proceedings of the Seventh International IUPAC Symposium, Tokyo, Japan, 16-19 August 1988.

10. Ibeh, N.I.; Oronsaye, P.I.; Unuabonah, U.I. Studies on Aflatoxin, Prenatal Exposure and Its Toxicosis in Adamawa Sate, North East of Nigeria. Appl. Food Biotechnol. 2014, 1, 29-33.

11. Underwood, M.A.; Gilbert, W.M.; Sherman, M.P. Amniotic Fluid: Not Just Fetal Urine Anymore. J. Perinatol. 2005, 25, 341-348. [CrossRef] [PubMed]

12. Suliburska, J.; Kocyłowski, R.; Komorowicz, I.; Grzesiak, M.; Bogdański, P.; Barałkiewicz, D. Concentrations of Mineral in Amniotic Fluid and Their Relations to Selected Maternal and Fetal Parameters. Biol. Trace Element Res. 2016, 172, 37-45. [CrossRef]

13. Woo, C.S.J.; El-Nezami, H. Maternal-Fetal Cancer Risk Assessment of Ochratoxin A during Pregnancy. Toxins $2016,8,87$. [CrossRef] [PubMed]

14. Ritieni, A.; Santini, A.; Mussap, M.; Ferracane, R.; Bosco, P.; Gazzolo, D.; Galvano, F. Simultaneous determination of mycotoxins in biological fluids by LC-MS/MS. Front. Biosci. 2010, 2, 151-158. [CrossRef] [PubMed]

15. Hatem, N.L.; Hassab, H.M.; Al-Rahman, E.M.A.; El-Deeb, S.A.; Ahmed, R.L.E.S. Prevalence of aflatoxins in blood and urine of Egyptian infants with protein-energy malnutrition. Food Nutr. Bull. 2005, 26, 49-56. [CrossRef] [PubMed]

16. Shuaib, F.M.B.; Jolly, P.E.; Ehiri, J.E.; Yatich, N.; Jiang, Y.; Funkhouser, E.; Person, S.D.; Wilson, C.; Ellis, W.O.; Wang, J.-S.; et al. Association between birth outcomes and aflatoxin B1biomarker blood levels in pregnant women in Kumasi, Ghana. Trop. Med. Int. Health 2010, 15, 160-167. [CrossRef]

17. Kyei, N.N.A.; Boakye, D.; Gabrysch, S. Maternal mycotoxin exposure and adverse pregnancy outcomes: A systematic review. Mycotoxin Res. 2020, 36, 243-255. [CrossRef] [PubMed]

18. De Vries, H.R.; Maxwell, S.M.; Hendrickse, R.G. Foetal and Neonatal Exposure to Aflatoxins. Acta Paediatr. 1989, 78, 373-378. [CrossRef]

19. Jonsyn, F.E.; Maxwell, S.M.; Hendrickse, R.G. Human fetal exposure to ochratoxin A and aflatoxins. Ann. Trop. Paediatr. 1995, 15, 3-9. [CrossRef]

20. Ahmed, H.; Hendrickse, R.G.; Maxwell, S.M.; Yakubu, A.M. Neonatal jaundice with reference to aflatoxins: An aetiological study in Zaria, northern Nigeria. Ann. Trop. Paediatr. 1995, 15, 11-20. [CrossRef]

21. Abulu, E.O.; Uriah, N.; Aigbefo, H.S.; Oboh, P.A.; Agbonlahor, D.E. Preliminary investigation on aflatoxin in cord blood of jaundiced neonates. West Afr. J. Med. 1998, 17, 184-187.

22. Abdulrazzaq, Y.M.; Osman, N.; Ibrahim, A. Fetal exposure to aflatoxins in the United Arab Emirates. Ann. Trop. Paediatr. 2002, 22, 3-9. [CrossRef]

23. Abdulrazzaq, Y.M.; Osman, N.; Yousif, Z.M.; Trad, O. Morbidity in neonates of mothers who have ingested aflatoxins. Ann. Trop. Paediatr. 2004, 24, 145-151. [CrossRef]

24. Turner, P.C.; Collinson, A.C.; Cheung, Y.B.; Gong, Y.; Hall, A.J.; Prentice, A.M.; Wild, C.P. Aflatoxin exposure in utero causes growth faltering in Gambian infants. Int. J. Epidemiol. 2007, 36, 1119-1125. [CrossRef] 
25. Dohnal, V.; Dvořák, V.; Malíř, F.; Ostrý, V.; Roubal, T. A comparison of ELISA and HPLC methods for determination of ochratoxin A in human blood serum in the Czech Republic. Food Chem. Toxicol. 2013, 62, 427-431. [CrossRef] [PubMed]

26. Malir, F.; Ostry, V.; Dofkova, M.; Roubal, T.; Dvorak, V.; Dohnal, V. Ochratoxin A levels in blood serum of Czech women in the first trimester of pregnancy and its correspondence with dietary intake of the mycotoxin contaminant. Biomarkers 2013, 18, 673-678. [CrossRef] [PubMed]

27. Kuiper-Goodman, T.; Scott, P.M. Risk assessment of the mycotoxin ochratoxin A. Biomed. Environ. Sci. 1989, 2, $179-248$.

28. Scudamore, K.A.; Patel, S.; Breeze, V. Surveillance of stored grain from the 1997 harvest in the United Kingdom for ochratoxin A. Food Addit. Contam. 1999, 16, 281-290. [CrossRef]

29. World Health Organization; International Agency for Research on Cancer. Some naturally occurring substances: Food items and constituents, heterocyclic aromatic amines and mycotoxins. In IARC Monographs on the Evaluation of the Carcinogenic Risk of Chemicals to Humans; WHO: Lyon, France, 1993; Volume 56, pp. 333-397.

30. Cheat, S.; Gerez, J.R.; Cognié, J.; Alassane-Kpembi, I.; Bracarense, A.P.F.L.; Raymond-Letron, I.; Oswald, I.P.; Kolf-Clauw, M. Nivalenol Has a Greater Impact than Deoxynivalenol on Pig Jejunum Mucosa in Vitro on Explants and in Vivo on Intestinal Loops. Toxins 2015, 7, 1945-1961. [CrossRef]

31. EFSA Panel on Contaminants in the Food Chain (CONTAM). Scientific Opinion on risks for animal and public health related to the presence of nivalenol in food and feed. EFSA J. 2013, 11, 3262. [CrossRef]

32. Rocha, O.; Ansari, K.; Doohan, F.M. Effects of trichothecene mycotoxins on eukaryotic cells: A review. Food Addit. Contam. 2005, 22, 369-378. [CrossRef] [PubMed]

33. Wells, L.; Hardie, L.; Williams, C.; White, K.; Liu, Y.; De Santis, B.; Debegnach, F.; Moretti, G.; Greetham, S.; Brera, C.; et al. Determination of Deoxynivalenol in the Urine of Pregnant Women in the UK. Toxins 2016, 8, 306. [CrossRef] [PubMed]

34. Rodríguez-Carrasco, Y.; Mañes, J.; Berrada, H.; Font, G. Preliminary Estimation of Deoxynivalenol Excretion through a 24 h Pilot Study. Toxins 2015, 7, 705-718. [CrossRef] [PubMed] 